IZA DP No. 5528

Scale Economies Can Offset the Benefits of Competition: Evidence from a School Consolidation Reform in a Universal Voucher System

Monique de Haan

Edwin Leuven

Hessel Oosterbeek

February 2011 


\title{
Scale Economies Can Offset the Benefits of Competition: Evidence from a School Consolidation Reform in a Universal Voucher System
}

\author{
Monique de Haan \\ University of Amsterdam and TIER \\ Edwin Leuven \\ CREST (ENSAE), CEPR, CESifo and IZA \\ Hessel Oosterbeek \\ University of Amsterdam, Tinbergen Institute, CESifo and TIER
}

\author{
Discussion Paper No. 5528 \\ February 2011
}

IZA

P.O. Box 7240

53072 Bonn

Germany

Phone: +49-228-3894-0

Fax: +49-228-3894-180

E-mail: iza@iza.org

\begin{abstract}
Any opinions expressed here are those of the author(s) and not those of IZA. Research published in this series may include views on policy, but the institute itself takes no institutional policy positions.

The Institute for the Study of Labor (IZA) in Bonn is a local and virtual international research center and a place of communication between science, politics and business. IZA is an independent nonprofit organization supported by Deutsche Post Foundation. The center is associated with the University of Bonn and offers a stimulating research environment through its international network, workshops and conferences, data service, project support, research visits and doctoral program. IZA engages in (i) original and internationally competitive research in all fields of labor economics, (ii) development of policy concepts, and (iii) dissemination of research results and concepts to the interested public.
\end{abstract}

IZA Discussion Papers often represent preliminary work and are circulated to encourage discussion. Citation of such a paper should account for its provisional character. A revised version may be available directly from the author. 
IZA Discussion Paper No. 5528

February 2011

\title{
ABSTRACT
}

\section{Scale Economies Can Offset the Benefits of Competition: Evidence from a School Consolidation Reform in a Universal Voucher System*}

\begin{abstract}
A large school consolidation reform in the Netherlands changed minimum school size rules underlying public funding. The supply of schools decreased by 15 percent, but this varied considerably across municipalities. We find that reducing the number of schools by 10 percent increases pupils' achievement by 3 percent of a standard deviation. A reduction in the supply of schools implies, for a given number of pupils, an increase in average school size. We present evidence that in our context scale economies dominated the effects of choice and competition. This points to an often ignored trade-off between scale and competition.
\end{abstract}

JEL Classification: $\quad$ I21, I22, H75, D40

Keywords: $\quad$ school choice, competition, school consolidation, achievement, economies of scale

Corresponding author:

Edwin Leuven

ENSAE

3, avenue Pierre Larousse

92245 MALAKOFF Cedex

France

E-mail: edwin.leuven@ensae.fr

\footnotetext{
This version: February 2011. We thank David Figlio and seminar participants in Amsterdam, Catanzaro, Leuven, Munich, Paris and Stockholm for their helpful comments. We also thank David Figlio for summarizing the main result of this paper in the haiku that is now the first part of the title.
} 


\section{Introduction}

According to economic logic, introducing and increasing school choice and competition is probably the most efficient and cost-effective education policy. The reasoning is simple and intuitive, more school choice and competition make it easier for parents to find a school that fits the specific needs of their children thereby enhancing allocative efficiency. At the same time it limits schools' market power thereby giving them an incentive to achieve productive efficiency. To implement this, Friedman (1955) proposed a system in which the government gives a specified amount of money for each child that parents can spend at the school of their choice, publicly or privately operated, as long as the school meets some minimum standards.

Despite this logic, few countries have implemented a system that is even remotely close to Friedman's proposed system. Moreover, the empirical evidence in support of school choice and competition is not clear-cut and far less convincing than the theoretical argument. There are two main reasons for this. The first is that many studies assess the partial-equilibrium effects of rather specific interventions such as small-scale voucher experiments, open enrollment or charter schools, that are often targeted at specific groups. The results of these studies cannot be generalized to system-wide school choice and competition. The other reason is that it has turned out to be very difficult to come up with sources of truly exogenous supply-driven variation in school choice and competition (Hoxby, 2009). This is particularly the case for studies that aim to identify the general equilibrium effects of school choice and competition. ${ }^{1}$

In this paper, we study the effect of school choice and competition on pupils' achievement in primary schools in the Netherlands. The primary school system in this country is very close to the system proposed by Friedman, and has been in place in that form since 1917. Parents can freely choose the school for their child irrespective of where they live and how much they earn, and all schools, publicly or privately operated, are funded by the central government through a "money follows pupil"-mechanism. The minimum standards schools have to meet in order to receive government funding, relate to educational quality which is monitored by the education inspectorate, and to the minimum number of pupils that is enrolled in a school.

To identify the effect of school choice and competition on pupils' achievement, we use a supply side reform that consisted of a change in the rule that determines the minimum number of pupils that has to be enrolled for a school to be eligible for funding. Before 1994 this rule was based on the number of inhabitants within a municipality whereas from 1994 onwards the rule relied on a municipality's pupil density. For many municipalities

\footnotetext{
${ }^{1}$ The next section provides further details of related studies.
} 


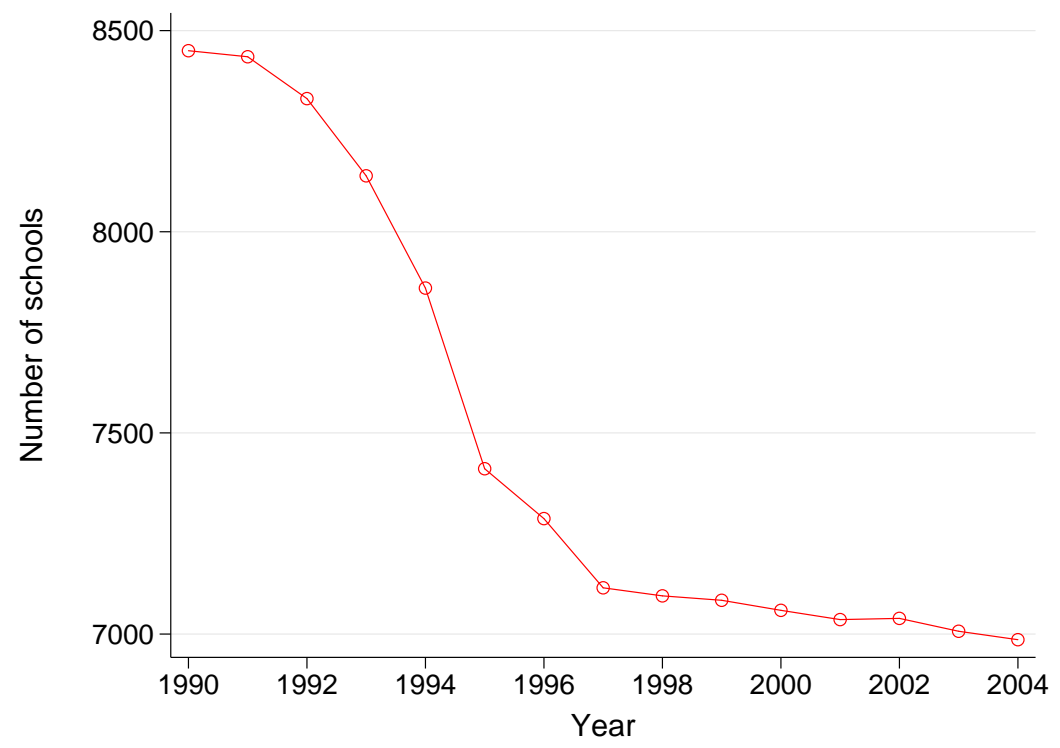

Figure 1. Number of primary schools in the Netherlands 1990-2004

the minimum required school size increased and many schools with a number of pupils above the old rule had a school size below the new rule. As a consequence the number of primary schools declined by about 15 percent. This can be seen in Figure 1, which shows the number of primary schools in the Netherlands by year for the period from 1990 to 2004. The decrease in the number of schools occurred between 1992 and 1996. This is due to the fact that the policy was announced in 1992 and that schools had until 1996 to comply with the new rule.

To investigate the effect of a reduction in the supply of schools on pupils' test scores, we exploit that the changes in the minimum required school sizes and the resulting changes in the number of schools varied across municipalities. In this paper we will use the number of schools in a municipality as measure of school choice and competition. A change in the number of schools in a municipality changes the number of schools from which parents can choose in their own municipality. A change in the number of schools in a municipality also changes the number of competitors with which the (remaining) schools in a municipality have to compete. ${ }^{2}$ We will focus on two cohorts of pupils; the last cohort of pupils who finished primary school before the policy was announced and the first cohort of pupils who enrolled in primary school when the policy was fully implemented.

\footnotetext{
${ }^{2}$ We prefer the number of schools in a municipality as measure of school choice and competition over a measure such as the Herfindahl index because we consider it more intuitive. Moreover, the Herfindahl index takes the size distribution of the schools into account. In the context of school choice it is not so clear why for a given number of schools, a different size distribution affects parents' choice set. Our results are, however, not dependent on the choice and competition measure that we use. In the appendix we report results based on the Herfindahl index instead of the number of schools.
} 
Using changes in the minimum required school size in a municipality as instrumental variable for the change in the number of schools in a municipality, we find that a 10 percent reduction in school choice and competition increases pupils' achievement by 3 percent of a standard deviation. To understand this seemingly counterintuitive result, it is important to realize that in a system with free choice, a reduction in the supply of schools not only implies a reduction in school choice but, for a given number of pupils, also implies an increase in average school size. In addition a reduction in the supply of schools may have an effect on school segregation, since fewer schools implies that there are fewer opportunities for pupils to sort among schools.

We present support for the hypothesis that in the setting in which the Dutch reform took place, scale economies dominate the effects of choice and competition. Before the reform, there were many schools that apparently operated at an inefficiently small scale. We also present evidence showing that school segregation did not change. We do not interpret our findings as evidence against the economic logic of school choice and competition. Instead, we draw attention to a trade-off between the benefits of choice and competition on the one hand and scale economies on the other hand. Our results show that at some point the latter may exceed the first. Our results are an illustration of the classical trade-off between market power and scale economies of anti-trust economics (Williamson, 1968).

The remainder of the paper continues as follows. The next section discusses how our contribution fits into the existing literature on school choice and competition. Section 3 provides information about the Dutch education system thereby focusing on existing mechanisms for parents to exercise choice and for schools to respond to that. Section 4 describes the details of the change in the minimum school size rule that we use as our source of exogenous supply-driven variation in school choice and competition. Section 5 introduces the data and Section 6 provides details of our estimation strategy. Section 7 presents and discusses the results and Section 8 summarizes and concludes.

\section{Related research}

In this section we briefly discuss how the research in this paper is related to different strands of the school choice and competition literature.

A first group of studies deals with choice programs such as voucher experiments, charter schools and changes in the set of schools from which students can choose. ${ }^{3}$ These

\footnotetext{
${ }^{3}$ For vouchers programs, see: Rouse (1998); Angrist et al. (2002); Peterson et al. (2003); Krueger and Zhu (2004); Angrist et al. (2006), for charter schools, see: Bettinger (2005); Hoxby and Rockoff (2005); Bifulco and Ladd (2006); Hanushek et al. (2007); Abdulkadiroglu et al. (2009); Imberman (2010), and for changes in the choice set, see: Cullen et al. (2006); Lavy (2010)
} 
studies typically examine the impact of the program on the achievement of the students that make use of it. The impact on other students (the peers that are left behind and the new peers) is usually ignored, and so are the effects through more competitive pressure on schools (see Ladd, 2002; Neal, 2002, for a discussion). Compared to the partial equilibrium effects that these studies estimate, our analysis looks at the average impact on all pupils in a municipality where the degree of school choice and competition has changed.

Closer to our research are the studies that examine the general equilibrium effects of system-wide variation in school choice and competition. The evidence from these studies is mixed. Hoxby (2000) looks at the impact of Tiebout choice in American public education on various indicators of achievement by exploiting variation in the number of school districts across metropolitan areas induced by variation in natural boundaries. She reports significantly positive effects of school choice and competition on achievement. To measure the effects of unrestricted choice on educational outcomes in Chile, Hsieh and Urquiola (2006) use the differential impact across municipalities that the provision of vouchers had on private enrollment. They find no evidence that choice improved average educational outcomes. However, they do find evidence that the program increased sorting, as the best public school students left for the private sector. Böhlmark and Lindahl (2008) use a similar approach to assess the impact of a voucher reform that was implemented in Sweden in 1992. While they find moderately positive short-term effects of an increase in the private school share, they fail to find any impact on medium or long-term educational outcomes. Gibbons et al. (2008) use discontinuities generated by admissions district boundaries to find that performance gains from greater school competition among English primary schools are limited. Finally, Card et al. (2010) use variation in the fractions of Catholics and of new homes across local areas in Ontario to find that competitive pressure has a significantly positive impact on test score gains.

Because of the transparency of our setup it is clear that we use a source of exogenous variation in school choice and competition that is completely supply side driven. Previous studies, for instance, Hsieh and Urquiola (2006) and Böhlmark and Lindahl (2008) have to assume that the variation in the entry of private schools across areas is supply driven conditional on time trends and covariates (cf. Hoxby, 2009). Likewise, Card et al. (2010) need to assume that, conditional on the joint share of Protestants and Catholics, the share of Catholics has no direct impact on outcomes. Also the results in Hoxby (2000) are not uncontested (cf. Rothstein, 2007; Hoxby, 2007). The starting point of our study also differs from that of previous studies. While most existing studies start from a situation with very limited choice, the starting point in this paper is a situation with a lot of choice being in place already for a long time.

Since the reform that we exploit in this paper led to school mergers, our work is 
also related to studies that deal with consolidation of schools or school districts (Berry, 2006; Berry and West, 2008; Brasington, 1999, 2003). Andrews et al. (2002) review the literature that is concerned with scale economies in education and conclude that "there is little convincing evidence in the United States on how consolidation actually affects school districts in the long-run." Kuziemko (2006) is interested in school size effects, and notes the lack of consensus in the literature concerning the relation between scale and achievement, and explains this by "the empirical weakness that the existing papers share", namely omitted variables bias. These studies focus on scale effects and ignore the effects of changes in competitive pressure. Our approach is different. We study the effects of school choice and competition in a context where a change in the number of schools necessarily also implies a change in average school size. We consider these two changes as joint elements. Previous studies focusing on school choice and competition have typically ignored scale effects, while previous studies focusing on consolidation or scale effects have typically ignored the effects of school choice and competition. ${ }^{4}$

\section{The Dutch education system}

Since the beginning of the 20th century the Dutch system of primary education resembles closely the voucher-system later proposed by Friedman. A key principle is "freedom of education". This has two components: Parents can freely choose the school for their child, and there is the freedom to start new schools and to organize the teaching in schools.

The freedom to choose a school is not restricted by where parents live (there are no school attendance areas) or how much they earn. With the exception of a few cases of orthodox religious schools, primary schools do not select pupils. Schools can grow or shrink from year to year, albeit within the limits of the speed with which they can adjust their capacity. If schools are oversubscribed, they typically follow a first-come, first-served rule. Applying this rule is facilitated by the system of rolling admissions. Children in the Netherlands are allowed to start school the day they turn 4 years old, and are required to start school the day they turn 5 years old. This system prevents that a large group of children applies to a school at the same time and is then informed that the school has no places available. Also, this system of rolling admissions provides more flexibility for schools to adjust their capacity.

There are public schools which provide education on behalf of the state, and private schools which are not set up by the state. Both types of schools receive funding from the central government through the same "money follows pupil"-mechanism. The funding of a school is thus based on the number of pupils enrolled. There is no additional funding

\footnotetext{
${ }^{4}$ Relating their work to that in Hoxby (2000), Berry and West (2008) acknowledge that any size effect they find also includes the effect of changes in competition.
} 
from local government agencies and there are no compulsory school fees. Schools are allowed to ask for a voluntary fee which is usually spent on extras, for example the yearly school trip. Schools cannot exclude pupils whose parents do not pay this voluntary fee from the regular school program. They can, however, exclude these pupils from the extras. Privately funded primary schools are virtually non-existent in the Netherlands.

Currently there are about 7000 primary schools in the Netherlands. For most pupils in the Netherlands the nearest primary school is within walking distance. For about 59 percent of the pupils the nearest school is less than 500 meters from their home and 89 percent of the pupils live less than 1 kilometer away from the nearest primary school (Bunschoten, 2008). About two thirds of pupils is enrolled in publicly-funded private schools. The main difference between public schools and publicly-funded private schools is that the latter are governed by a private school board and the first are governed by the municipality. Historically most private schools were founded on the basis of religious beliefs (mainly Protestantism and Catholicism).

To be eligible for government funding, schools have to satisfy two requirements. The first comes in the form of quality standards. For example, the government sets a number of core objectives. These core objectives state what skills and knowledge pupils should have at the end of (primary) school. Whether these core objectives are achieved is checked by the educational inspectorate, which monitors schools for compliance with laws and regulations.

The second requirement concerns the number of pupils at a school. To start a new school the number of pupils enrolled in the school should within a specified period after the start-up exceed a certain threshold (that applies for new schools). For existing schools a different set of minimum school size rules applies, which are in general lower than the rules for new schools. In order to be eligible for government funding an existing school should have a number of pupils which is above the minimum school size rule. The minimum required school sizes are set by the central government but vary between municipalities. This will be described in more detail in the next section.

Primary education in the Netherlands covers eight grades; children enter primary school between their fourth and fifth birthday, and unless they repeat a grade, leave primary school at the age of 11 or 12 . At the end of primary school children make a national exit test which assesses their level in arithmetic, language and information processing. Pupils' performance on this test is used to track them into secondary schools. We use the test results as our outcome variable in the analyses. 


\section{The reform}

Primary schools in the Netherlands must comply with the minimum school size rule in order to be eligible for funding. This rule stipulates the minimum number of pupils that should be enrolled in a school. In the 1980's there were concerns about the size of the schools. There were many small schools and there were doubts about the ability of small schools to provide education of sufficient quality (Ministry of Education, 1990). In addition, the funding system was such that each school received a fixed amount plus an amount depending on the number of pupils. Many small schools were thus more expensive than a smaller number of bigger schools. For these reasons a project was started in the beginning of the 1990's, which resulted in an overall change in the minimum school size rule which was established in a law that took effect on January 1, 1994.

Before 1994 the funding of a school was ended on August 1 when during the previous three school years the school had fewer pupils than the number required under the Primary Education Act (Staatsblad 1986, 256, WBO). ${ }^{5}$ The required numbers of the Primary Education Act were based on the number of inhabitants of the municipality in which the school was located. The minimum school size depended on the number of inhabitants according to the following step function:

$$
\text { minimum school size }= \begin{cases}50 & \text { if \#inhabitants }<25,000 \\ 75 & \text { if } 25,000 \leq \# \text { inhabitants }<50,000 \\ 100 & \text { if 50,000 } \leq \# \text { inhabitants }<100,000 \\ 125 & \text { if \#inhabitants } \geq 100,000\end{cases}
$$

So for example, if a school was located in a municipality with 30,000 inhabitants and had less than 75 pupils for three consecutive years, the funding was stopped at the beginning of the next school year in case of a privately-run school or was closed down in case of a publicly-run school. ${ }^{6}$

On July 11, 1992 the new minimum school size rule was published in the weekly magazine that is sent to all schools. Although the new rule was published in 1992, the old rule applied until January 1, 1994. The new minimum school size rule was no longer based on the number of inhabitants of the municipality, instead the new rule was based on

\footnotetext{
${ }^{5}$ A school year starts on August 1 of a given year and ends on July 31 the following year.

${ }^{6}$ If a privately-run school stops receiving funding from the government this means in practice that it has to close down. The only source of funding is the funding of the government since schools are not allowed to charge school fees.
} 
the pupil density of the municipality according to the following formula:

$$
\text { minimum school size }=\frac{d_{m}}{0.25+0.0045 * d_{m}}
$$

whereby $d_{m}$ is pupil density in municipality $m$ defined as the number of inhabitants between 4 and 11 years old divided by the size of the municipality in square kilometers.

Figure 2 shows scatter plots of the old and new minimum school size rules. The first panel shows a scatter plot of the old and new rules against the number of inhabitants. The circles connected by the line show the old minimum school size rule, each circle represents a municipality. All municipalities with less than 25,000 inhabitants have a minimum school size of 50 , at 25,000 there is a jump to 75 , at 50,000 there is a jump to 100 and all municipalities with more than 100,000 inhabitants have a minimum school size of 125 . The crosses show the new minimum school size rule, the new minimum school size ranges from 23 pupils to 200 pupils. As can be seen in the first panel there is a lot of variation in the new minimum school size between municipalities with the same number of inhabitants, and thus the same minimum school size before the reform.

The second panel in Figure 2 shows the old and new rules by pupil density. The new minimum school size rule, shown by the crosses, shows a clear relation with pupil density. ${ }^{7}$ Municipalities with the same pupil density have the same minimum school size after the reform but as the dots show, the old minimum school size could be very different for municipalities with the same pupil density.

The new rule was introduced in 1994 but there was a grace period of two years. No schools were forced to close down or stopped receiving funding in the school years $1994 / 1995$ and 1995/1996. If a school had a number of pupils below the rule in the school years 1994/1995 and 1995/1996 the school stopped receiving funding from August 1, 1996 in case of a private school or was closed down in case of a public school. From 1996 onward all schools with a number of pupils below the minimum school size for two school years (either consecutive or with one year in between) were closed down/ stopped receiving funding from the beginning of the next school year.

On average the minimum school size increased due to the reform. Figure 3 shows the average minimum school size by year as well as the average number of schools in a municipality by year. The vertical axis on the left shows the average number of schools and the vertical axis on the right shows the average minimum school size. Until 1993 the average minimum school size was just above 60 pupils. In 1994, after the implementation of the law, the average minimum school size jumped to about 100. At the same time the average number of schools declined. In 1991 municipalities had on average 16.5 schools,

\footnotetext{
${ }^{7}$ There are some "outliers" which are due to the fact that if the pupil density was more that 500 it was set at 500 and when the size of the municipality was smaller than $10 \mathrm{~km}^{2}$ it was set at 10 .
} 

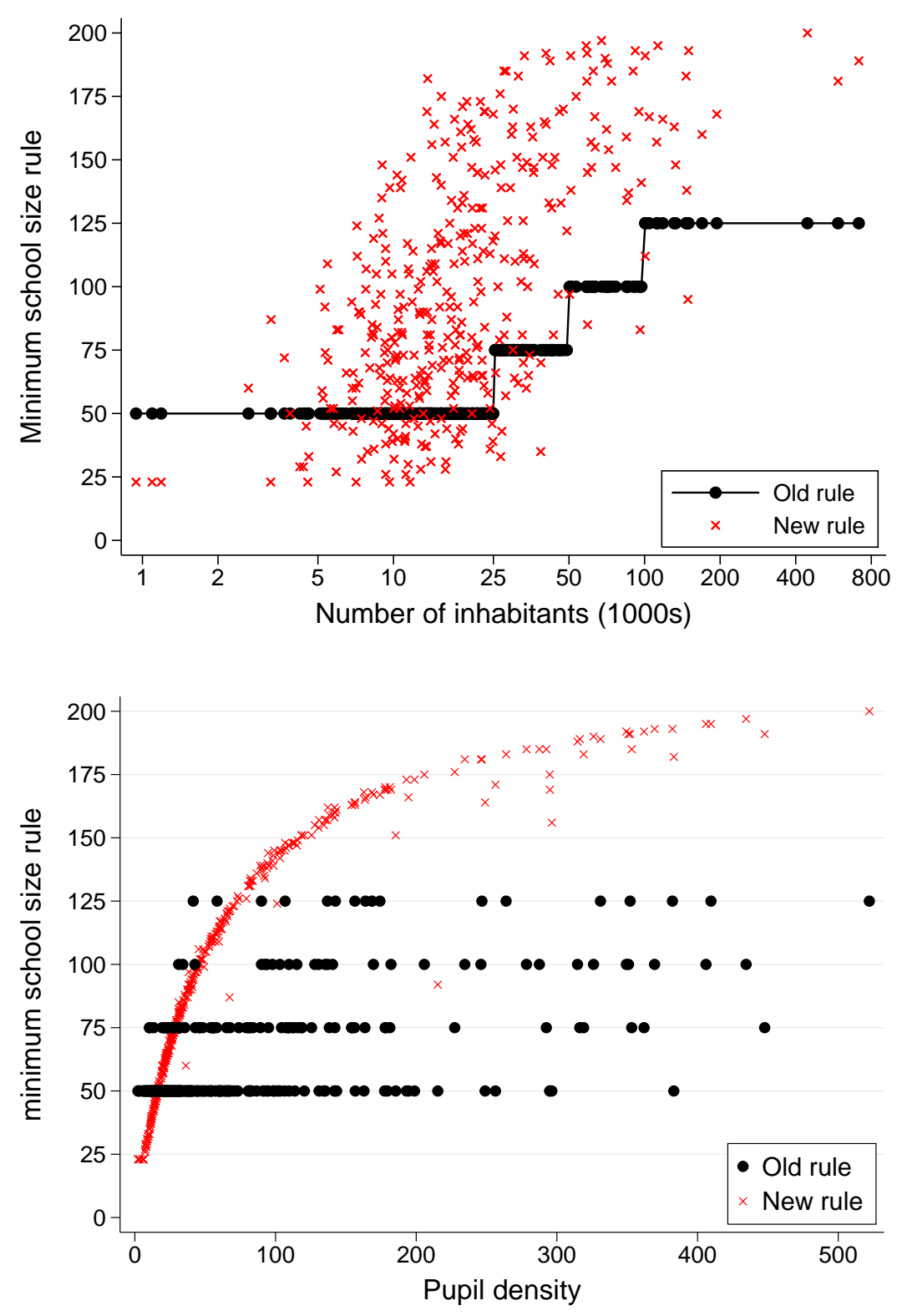

Figure 2. Old and new rules by number of inhabitants and pupil density in 1992 


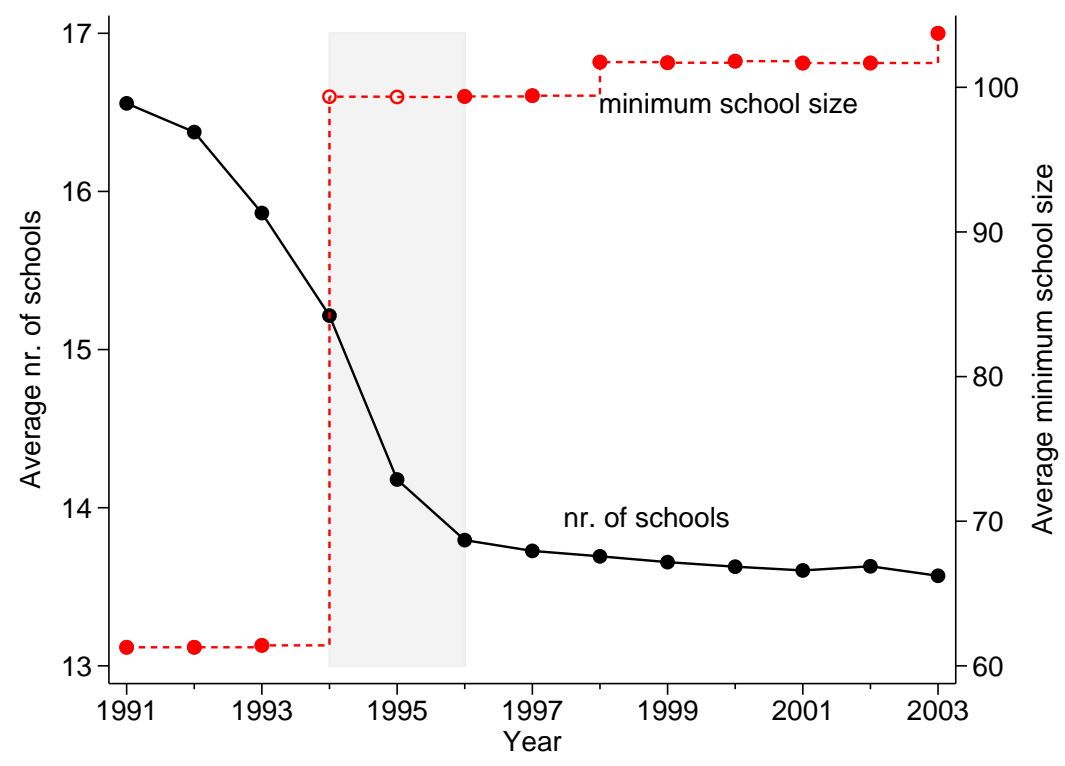

Figure 3. Average number of schools and minimum school size rules by year

but after 1992 the number of schools started declining until 1997 when it stabilized around an average of 13.5 schools per municipality. In total the number of schools declined from 8362 schools in 1992 to 7100 schools in 1997, a decline of $15 \%$ within a period of five years. ${ }^{8}$

Most schools that were below the new rule in 1994, merged with another school instead of being closed down on August 1, 1996. Of the 8362 primary schools in 1992, 2293 schools were part of a merger in the five years between 1992 and 1997. Most of these mergers were real mergers and not administrative mergers as is reflected by the fact that the number of school locations declined to 7163 in $2003 .{ }^{9}$

\section{Data}

We use data from various sources. As outcome variable we use standardized test scores. At the end of primary school pupils take a nationwide test developed by the national institute for educational testing and measurement. This test determines for a large part

\footnotetext{
${ }^{8}$ The reform affected private and public schools similarly. We do not have access to schools' denomination in our micro data, but from aggregate statistics we know that the share of public schools remained approximately constant between 1992 and 1997, 35\% vs. $33.5 \%$.

${ }^{9}$ There were not only changes in the minimum school size rules for existing schools, but the minimum school size rules for new schools also changed due to the reform. Before the reform the minimum school size for new schools was $\frac{8}{5}$ times the minimum school size for existing schools. After the reform the minimum school size for new schools is $\frac{10}{6}$ times the minimum school size for existing schools with a minimum of 200. In principle this gives us a second instrumental variable. In practice, however, the two instruments are too highly correlated for the second instrument to give any leverage.
} 
the type of secondary school a pupil will go to after primary school. Although the test is not compulsory for pupils, most pupils take the test. The test consists of multiple choice questions that deal with language, arithmetic/mathematics, information processing and environmental studies (optional). The test is administered on three days in February and at the end of the last day the answer sheets are sent to the testing institute, where they are marked. The results for each pupil are sent back to the school. The score is based on the number of correct answers for language, arithmetic/mathematics and information processing. For the analysis in this paper we standardized the scores by year, so that results can be interpreted in terms of standard deviation units of the annual test score distribution.

Data at the school level for all primary schools in the Netherlands, such as information about school size and the share of minority pupils, are obtained from the Dutch Ministry of Education. Data at the municipality level are obtained from Statistics Netherlands. The minimum school size rules are collected from Het Staatblad $(1986,1993)$ that publishes (changes in) laws and from Gele Katern, a magazine for schools.

During our observation period some municipalities merged. Because a municipality merger can lead to changes in pupil density it will trigger changes in the minimum required school size. A merger between municipalities however also leads to other changes related to local governance. The analysis in this paper will therefore be based on the municipalities that were not part of a merger between 1992 and 2004. ${ }^{10}$ About $20 \%$ of the municipalities in 2004 are a result of a merger, the analysis will thus be based on the remaining $80 \%$ of the municipalities.

In the analysis we will compare two cohorts of pupils; the cohort of pupils that finished primary school in 1992, before the change in the number of schools, and the cohort of pupils that enrolled in primary school after the large reduction in the number of schools and who were therefore not directly affected by the school mergers. This is the cohort of pupils who finished primary school in 2003.

Table 1 shows summary statistics separately for the years 1992 and 2003. The bottom panel of the table shows the substantial changes that took place in the average number of schools and the average minimum school sizes. We also see that the numbers of inhabitants and pupils increased increased by 7 to 10 percent. The top part of the table shows that the number of pupils that took the test increased much more than the number of pupils. This is not problematic for the analysis as long as the change in test-taking pupils is unrelated to the changes in the minimum school sizes rules. The results in Table A in the Appendix show that the change in the share of test-takers (ratio of test-takers to number of 11-year-olds in municipality) is not significantly related to the change in the

\footnotetext{
${ }^{10}$ We take 2004 as end date because the school year 2003 starts in August 2003 but ends in June 2004
} 
Table 1. Summary statistics

\begin{tabular}{|c|c|c|c|c|}
\hline & \multicolumn{2}{|c|}{1992} & \multicolumn{2}{|c|}{2003} \\
\hline & mean & SD & mean & SD \\
\hline \multicolumn{5}{|l|}{ Test scores } \\
\hline Standardized score & -0.02 & 1.01 & -0.02 & 1.01 \\
\hline$N$ & \multicolumn{2}{|c|}{71283} & \multicolumn{2}{|c|}{111226} \\
\hline \multicolumn{5}{|l|}{ Municipality Characteristics } \\
\hline Number of schools & 17.31 & 21.09 & 14.35 & 18.18 \\
\hline Minimum school size (existing schools) & 62.25 & 21.06 & 101.07 & 47.57 \\
\hline Number of pupils $(\times 1000)$ & 2.97 & 4.72 & 3.24 & 5.20 \\
\hline Number of inhabitants $(\times 1000)$ & 31.89 & 59.92 & 34.22 & 62.47 \\
\hline Share minority pupils & 0.05 & 0.06 & 0.06 & 0.07 \\
\hline$N$ & \multicolumn{2}{|c|}{345} & \multicolumn{2}{|c|}{345} \\
\hline
\end{tabular}

minimum school size rule.

\section{Empirical approach}

Before we present the empirical results, we first spell out which empirical specifications we will estimate and on which identifying assumptions these are based.

We are interested in the effect $(\delta)$ of the number of schools in municipality $m$ in year $t\left(s_{m t}\right)$ on the test scores of pupil $i$ in that municipality in that year $\left(y_{i m t}\right)$. We postulate the following relationship:

$$
y_{i m t}=\alpha+\delta \cdot \ln \left(s_{m t}\right)+\lambda_{m}+\mu_{t}+\varepsilon_{i m t}
$$

whereby $\lambda_{m}$ is a vector of municipality fixed effects, $\mu_{t}$ are year fixed effects, $\varepsilon_{i m t}$ is an idiosyncratic error term which we allow to be clustered at the municipality level.

Since the effect of a change in the number of schools by 1 is likely to be very different in a municipality with 4 schools than in a municipality with 40 schools we do not include the number of schools as explanatory variable but instead we use the logarithm of the number of schools. In this case we can interpret $\delta$ as the effect of a $100 \%$ change in the number of schools on pupil test scores.

Equation (1) includes municipality fixed effects. This is already an improvement over a cross-sectional regression of test scores on the number of schools in a municipality. This latter approach will produce biased estimates if municipalities with more or fewer 
schools are systematically different. The fixed effects specification takes out such systematic differences and only exploits within municipality changes in the number of schools. In addition we include year fixed effects which control for changes over time which are the same across municipalities, such as education policies which are implemented nationwide.

Changes in the number of schools within a municipality may however be due to changes in unobserved municipality characteristics. For example, a change in the composition of the population of the municipality might change the demand for schools, and in addition have a direct impact on pupil test scores, leading to omitted variable bias. We will therefore use an instrumental variable approach whereby we instrument the change in the number of schools in a municipality between 1992 and 2003 by the immediate change in the minimum required school size due to the change in rules.

Since the old and new minimum required school sizes are calculated based on the number of inhabitants and pupil density in 1992, our instrument will not pick up changes in the number of inhabitants or pupil density over time. The variation in our instrument comes from differences between municipalities in the ratio of pupil density and the number of inhabitants in 1992. If these municipalities also differ in other (unobserved) characteristics this will be captured by the municipality fixed effects. Our identifying assumption is thus that the change in a municipality's minimum required school size and the change in the average residual achievement of pupils in that municipality are mean independent. ${ }^{11}$

Although there are no specific reasons to believe that trends in test scores between municipalities with different ratios of pupil density and the number of inhabitants would be systematically different in absence of a change in the minimum school size rule, the assumption would be weaker if we could condition on municipality-specific time trends. This is not feasible because we only have observations from two years. To relax the assumption of a common trend for all municipalities in the form of $\mu_{t}$, we allow the year fixed effect to vary across four groups of municipalities of different size. ${ }^{12} 13$

In the next section we will start with presenting the difference-in-difference results

\footnotetext{
${ }^{11}$ Whereby the change in minimum school size and the change in average residual pupil achievement are measured as deviations from a nation wide trend, since we include year fixed effects in our specification.

${ }^{12}$ Municipalities are divided into 4 categories based on the number of inhabitants: (0-25000), (2500050000), (50000- 100000) and (100000 or more). Trends in test scores are allowed to differ between these four categories.

${ }^{13}$ A scenario under which the exclusion restriction might fail is if closeness to the minimum required school size gives an incentive to schools to perform and if, in addition, the share of schools in a municipality that are close to the norm is correlated with the instrument. As a robustness check we include the share of schools in a municipality that are at most 25 pupils (about 10 percent of average school size) away from the norm in equation (1). The coefficient for this variable is not significantly different from zero. Moreover, the estimated coefficient of $\ln$ (number of schools) remains the same.
} 
Table 2. Difference in differences results

\begin{tabular}{lccc}
\hline & $(1)$ & $(2)$ & $(3)$ \\
\hline $\ln$ (number of schools) & -0.05 & -0.08 & -0.03 \\
& $(0.08)$ & $(0.07)$ & $(0.07)$ \\
Year fixed effects & Yes & Yes & Yes \\
Municipality fixed effects & Yes & Yes & Yes \\
Control variables & - & Yes & Yes \\
Allowing for different trends large & - & - & Yes \\
and small municipalities & & & \\
Nr municipalities & 345 & 345 & 345 \\
Nr observations & 182509 & 182509 & 182509 \\
\hline
\end{tabular}

Note: Dependent variable is standardized test score. Standard errors in parentheses are clustered at the municipality level. Control variables: $\ln (\mathrm{nr}$. pupils), $\ln (\mathrm{nr}$. inhabitants) and municipality share of ethnic minority pupils. Trend in test scores between 1992 and 2003 are allowed to differ between municipalities with number of inhabitants of respectively (0-25000), (25000-50000), (50000-100000) and (100000 or more).

without using the change in minimum required school size as instrument for the change in the number of schools. We will show results with and without control variables. Subsequently we will present our instrumental variables results. Since one may wonder whether pupils and schools in the southern part of a large city are affected by the number of schools in the northern part of the city, we will also present estimates whereby we exclude the 20 biggest municipalities, those with more than 100,000 inhabitants (in 2003).

\section{Results}

\subsection{Difference-in-differences estimates}

We start with presenting fixed-effect results which can be interpreted as naive differencein-differences estimates which ignore the possible endogeneity of the change in the number of schools in a municipality. Column 1 of Table 2 shows a regression of pupil test scores on the number of schools in the municipality including municipality and year fixed effects, thereby controlling for (unobserved) differences between municipalities that are constant over time and for changes over time that are constant across municipalities. ${ }^{14}$ The result in column 1 indicates that a $10 \%$ reduction in the number of schools is associated with an increase in test scores of about $0.5 \%$ of a standard deviation, which is very small and not significantly different from zero.

If changes in the number of schools are correlated to changes in other municipality

\footnotetext{
${ }^{14}$ See Appendix Table B1 for results using the Herfindahl index as measure of school choice and competition.
} 
characteristics affecting pupil test scores, this will lead to omitted variables bias. Column 2 therefore shows the results when changes in the number of inhabitants, changes in the number of pupils and changes in the share of minority pupils in the municipality are included as control variables. The coefficient in column 2 is negative and a bit larger in absolute value than the coefficient in column 1 but also not significantly different from zero. Column 3 shows results where trends in test scores between 1992 and 2003 are allowed to differ between municipalities with a different number of inhabitants. The coefficient in column 3 is a bit smaller in absolute value compared to the estimates in columns 1 and 2 but still negative, small and not significantly different from zero.

\subsection{Instrumental variable estimates}

Since the results in Table 2 might suffer from endogeneity problems we want to isolate the change in the number of schools which is due to the reform, by using the change in minimum school size rules as instrument. In order to avoid weak instrument problems the effect of the change in rules on the change in schools should be sufficiently strong. Figure 4 shows a scatter plot of the percentage change in the number of schools against the percentage change in the minimum school size rule. On average the reduction in the number of schools was $15 \%$ but, as Figure 4 shows, there was quite some variation in the change in the number of schools. Some municipalities had no change in number of schools while other municipalities faced a reduction in the number of schools of $50 \%$.

Figure 4 also shows a linear fit of the change in the number of schools schools on the change in rules. There is a strong negative relation. This is confirmed in column 1 of the top panel of Table 3, which shows the result of a regression of the logarithm of the number of schools on the logarithm of the minimum school size rule including municipality and year fixed effects and controlling for changes in a number of municipality characteristics. The results in column 1 show that a $100 \%$ increase in the minimum school size rule leads on average to a reduction in the number of schools of $19 \%$ which is significant at the 1 percent level and has a partial F-statistic of 86.1.

The second stage results in the first column of Table 3 use minimum school size as instrument for the number of schools. Compared to the results in Table 2 the coefficient estimate in column 1 of Table 3 is larger in absolute value and significantly different from zero at a 5 percent significance level. The results show that a $10 \%$ reduction in the number of schools increases test scores on average by $3 \%$ of a standard deviation. ${ }^{15}$

The second columns in Tables 3 show the first stage and second stage results when the 20 biggest municipalities (those with more than 100000 inhabitants) are excluded from

\footnotetext{
${ }^{15}$ Equivalent first stage and 2SLS results based on the Herfindahl index instead of the number of schools are presented in Appendix Table B2.
} 


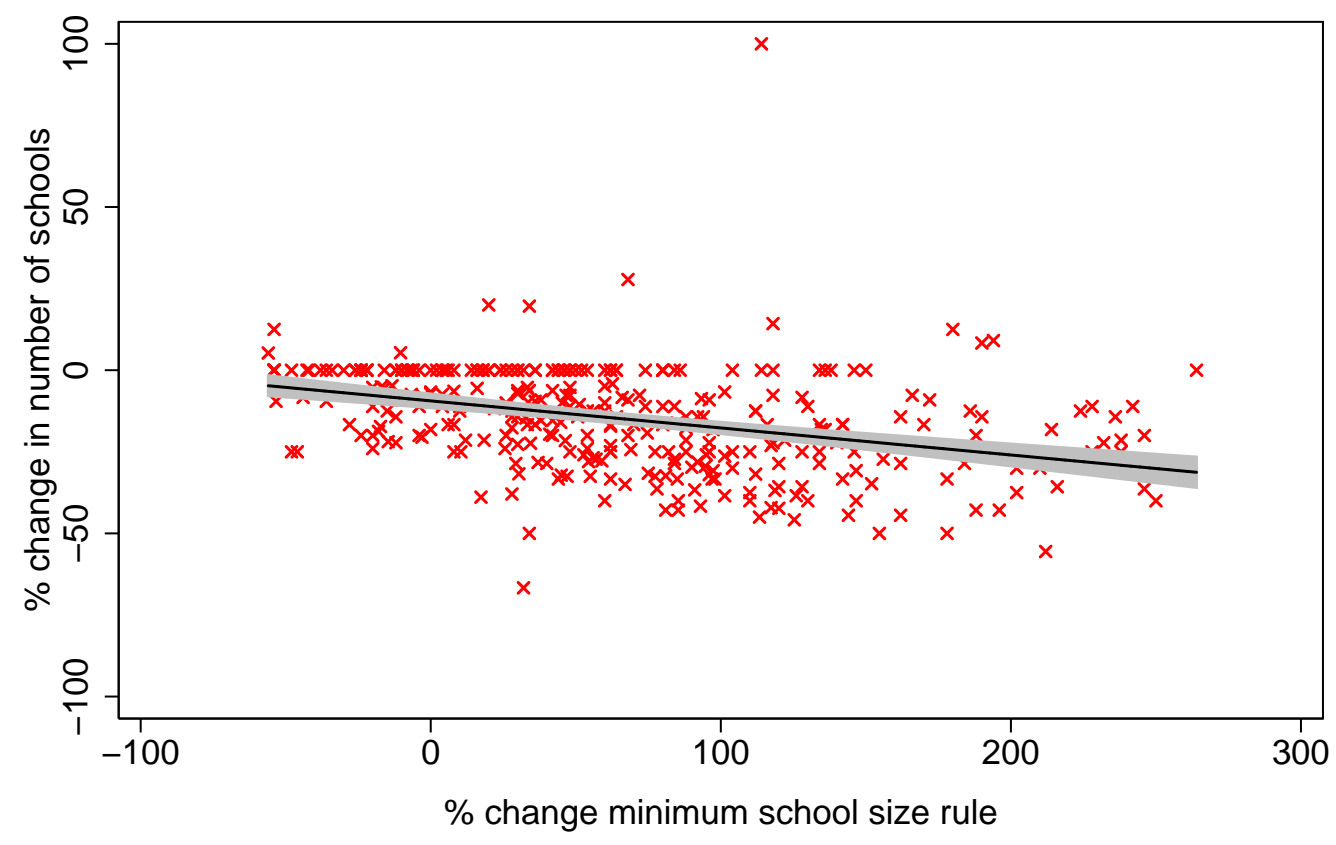

Fitted values $\quad 95 \% \mathrm{Cl}$

Figure 4. Change in rules and schools

Table 3. Main results: first and second stage

(1)

First-stage:

$\ln$ (minimum school size)

$-0.19^{* * *}$

$(0.02)$

$-0.18^{* * *}$

Partial F-statistic

86.1

94.3

Second-stage:

$\ln$ (number of schools)

$-0.28^{* *}$

$(0.13)$

Excluding biggest 20 municipalities

Yes

$\mathrm{Nr}$ municipalities

$\mathrm{Nr}$ observations

Note: Dependent variable in second stage is standardized test scores. Standard errors are clustered at the municipality level. * significant at the $10 \%$ level, ** significant at the $5 \%$ level, *** significant at the $1 \%$ level. All regression include municipality fixed effects, year fixed effect, control variables: $\ln (\mathrm{nr}$. pupils), $\ln$ (nr. inhabitants), municipality share of ethnic minority pupils and trends are allowed to differ between municipalities with number of inhabitants of respectively (0-25000), (25000-50000), (50000-100000) and (100000 or more). 
the analysis. This does not affect our findings.

The results in Table 3 show that a reduction in choice due to a reduction in the supply of schools has a small positive impact on pupil performance. This is not what we expect on the basis of the theoretical arguments for school choice and competition: With more school choice it should be easier for parents to find the school that matches their preferences and the needs of their child. In addition more schools should lead to more competition and a resulting increase in school quality. On the basis of these two mechanisms we would expect that a decrease in the supply of schools would have a negative impact on pupil performance.

In the next two subsections, we examine two potential explanations for our findings. The first is often discussed in the school choice literature: More school choice could lead to more sorting with potential adverse effects on school performance of (some) pupils. The second potential explanation concerns economies of scale in education, something which is rather underexplored in the literature on school choice. More school choice in the form of more schools will for a given number of pupils always imply smaller schools and if there are economies of scale this might adversely affect pupil performance.

\subsection{Segregation}

We first investigate whether the decline in the supply of schools, due to the reform, affected sorting of pupils among schools. For each primary school we know not only the number of pupils attending the school but also the number of pupils in each of the following three categories; 1) pupils with low educated migrant parents, 2) pupils with low educated Dutch parents and 3) all pupils that do not fall in the first two categories. Given this division of pupils by socioeconomic status we can calculate a relative heterogeneity index as in Urquiola (2005). Urquiola investigates the effect of school choice on sorting by investigating the impact of the number of school districts on the (racial/educational) heterogeneity of a school district relative to the heterogeneity of the metropolitan area in which the district is located. This measure of heterogeneity is defined as $H=1-\sum_{r=1}^{R} S_{r}^{2}$ where $R$ is the number of groups and $S_{r}$ is the share of group $r$ in the population.

On the basis of the division into the groups defined above we can calculate the heterogeneity index for each school and for the municipality in which the school is located. By taking the ratio of the two we obtain a measure of relative heterogeneity. There is one issue though which is that the definition of the second category (pupils with low educated Dutch parents) changed between 1992 and 2003. In 1992 all children with at least one parent that had at most the lowest level of secondary education were included in this category. In 2003 pupils were only included in the second category when both parents had at most the lowest level of secondary education. Since this change in the definition 
Table 4. Effect of the number of schools on sorting

\begin{tabular}{lcccc}
\hline & \multicolumn{4}{c}{ \# Groups in Heterogeneity Index } \\
\cline { 2 - 5 } & \multicolumn{2}{c}{3} & Mean & S.D. \\
\hline Summary statistics & Mean & S.D. & 0.12 & 0.15 \\
Heterogeneity index school & 0.36 & 0.20 & 0.17 & 0.14 \\
Heterogeneity index municipality & 0.44 & 0.14 & 0.86 & 1.23 \\
Relative heterogeneity index & 0.84 & 0.57 & & \\
Results & & & 0.14 & \\
ln(number of schools) & -0.08 & & $(0.15)$ & \\
& $(0.09)$ & & 104.64 & \\
Partial F-statistic first stage & 105.02 & & 11391 & \\
Nr. observations (schools) & 11403 & & & \\
\hline
\end{tabular}

Note: Dependent variable is school heterogeneity (relative to municipality heterogeneity). Estimates come from 2SLS regressions. Standard errors in parentheses are clustered at the municipality level. All regression include municipality fixed effects, year fixed effect, control variables: $\ln$ (nr. pupils), $\ln (\mathrm{nr}$. inhabitants), and trends are allowed to differ between municipalities with number of inhabitants of respectively (0-25000), (25000- 50000), (50000- 100000) and (100000 or more).

of the second category applied for all schools in all municipalities in the Netherlands this should be captured by the year fixed effect and therefore not affect the results. As an additional robustness check we calculate the (relative) heterogeneity index on the basis of two groups; 1) pupils with low educated migrant parents and 2) all other pupils. The index based on this division is not affected by the change in the definition of the second category.

Table 4 shows 2 SLS results of the effect of the number of schools on the two measures of relative heterogeneity, using the minimum school size rule as instrument. The result shows that there is no significant impact of the change in the supply of schools on sorting of pupils in terms of socioeconomic status. The estimates are small and not significantly different from zero. This indicates that sorting cannot explain our findings.

\subsection{Economies of scale}

The change in the supply of schools affected school size. This can be seen from the kernel densities of school size for the years 1992 and 2003 in Figure 5. Average school size increased from 169 pupils in 1992 to about 221 pupils per school in 2003. The increase in average school size can explain our findings if there are economies of scale. In this subsection we provide two pieces of evidence for this to be the case. First, we present results from a survey among school principals suggesting that increases in school size are 


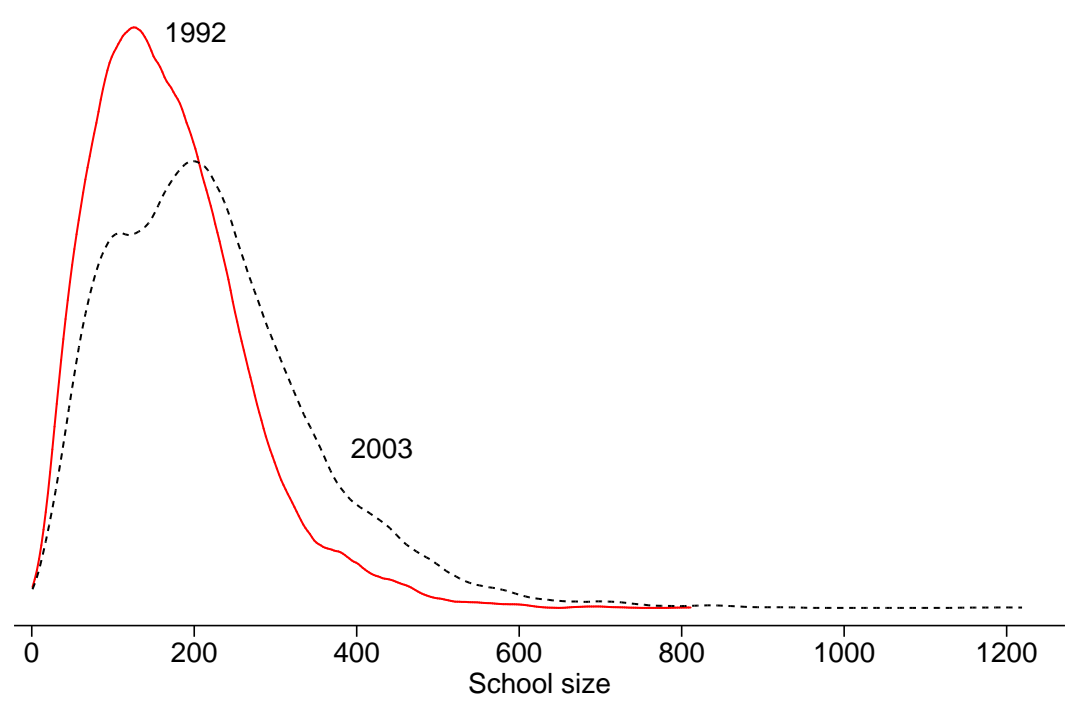

Figure 5. Kernel density of school size in 1992 and 2003

beneficial for some processes relevant for pupils' performance. Second, we extend our previous 2SLS regressions by including school size, and find that the effect of the number of schools in a municipality is no longer significantly different from zero.

In the year of the announcement of the change in the minimum school size rule (1992), a survey was conducted which asked principals of 177 primary schools in the Netherlands, among other things, about the organization of teaching in their schools and about the schools' contacts with parents. ${ }^{16}$ In Table 5, we report results from regressions of these organizational features and school-parent contacts on the size of the school. Each row comes from a different regression. The results show that larger school size is associated with (i) less teaching by the principal, (ii) a higher probability of having at least one full time director, (iii) fewer classes with pupils from multiple grades, and (iv) a higher probability of having a remedial teacher. At the same time a larger school is not associated with less involvement of the parents with the school (as indicated in the second half of the table). These findings are consistent with the view that just before the reform was implemented, increases in school size would increase the efficiency of the teaching process while it would not harm parental involvement.

To disentangle the effect of the change in school choice and competition and the effect of the change in school size, we augment equation (1) with school size:

$$
y_{\text {imt }}=\alpha+\delta \cdot \ln \left(s_{m t}\right)+\psi \cdot \ln \left(\text { school size } e_{i m t}\right)+\lambda_{m}+\mu_{t}+e_{\text {imt }}
$$

\footnotetext{
${ }^{16}$ This survey is part of a larger project that collected data from primary school pupils, their parents and teachers; the Landelijke Evaluatie Onderwijsvoorrangsbeleid. We only use information from the representative sample of schools.
} 
Table 5. Associations between school size and school characteristics

\begin{tabular}{lc}
\hline Dependent variable: & $\ln ($ school size $)$ \\
\hline Share of time the principal spends on teaching. & $-0.139^{* * *}$ \\
& $(0.023)$ \\
Probability the school has at least one full time director. & $0.233^{* * *}$ \\
& $(0.044)$ \\
Share of classes that contain pupils from multiple grades. & $-0.575^{* * *}$ \\
& $(0.045)$ \\
Probability school has a remedial teacher. & $0.181^{* *}$ \\
Probability school is involved in extracurricular parent-pupil activities & $(0.052)$ \\
Probability school has agreement with parents about: & -0.020 \\
parents attending parent-teacher meetings . & $(0.053)$ \\
& \\
discussing the school report of the pupils. & -0.002 \\
time spend on the different subjects. & $(0.062)$ \\
minimum goals that pupils should achieve & 0.002 \\
& $(0.023)$ \\
\end{tabular}

Note: Robust standard errors in parentheses. ** significant at the 5\% level, *** significant at the $1 \%$ level. Results are based a survey among principals of 177 schools in 1992. 
where $\psi$ is the scale effect.

We estimate this specification with OLS, but a concern is the potential endogeneity of school size. Schools can be large because they are good and popular. In addition to our OLS estimates we therefore also instrument school size. We will use variation in the number of pupils at the municipality level as instrument for school size. The advantage of this instrument is that it varies across municipalities while we expect the major source of endogeneity to come from sorting across schools within a municipality. We continue to control for (the log of) the number of inhabitants. For our instrument to be valid we require shocks to the population share of pupils over time not to have an independent effect on achievement. ${ }^{17}$

The first column in Table 6 reports the estimates of the baseline specification but excludes the number of pupils from the list of covariates which was included to gain precision in the specifications in Table 3. It is reassuring to see that this does not affect the results. It also confirms the exogeneity of our main instrument for the number of schools. Column 2 then shows the results when the logarithm of school size is included in the specification. The coefficient on the logarithm of the number of schools is reduced by half of its original value and is no longer significantly different from zero. The coefficient on the school size variable on the other hand indicates that test scores increase with school size.

The final column reports the estimates where (ln) school size is instrumented with the (ln) number of pupils in the municipality. Since the specification includes municipality fixed effects, changes in school size are essentially instrumented with changes in the population share of pupils. As can be seen in the table, we have good first-stages for both our endogenous variables. The estimated size effect is very close to the one we found using OLS, and is close to being significant at the $10 \%$-level. A Hausman test does not reject the null hypothesis that school size is exogenous in (2). ${ }^{18}$ In the final column, the coefficient on the logarithm of the number of schools is further reduced (in absolute size) and stays insignificant. These results are consistent with the reasoning that the negative effect of the reduction in the supply of schools is explained by positive effects of an increase in school size.

\section{Conclusion}

In this paper we have analyzed the impact of variation in the number of schools in a municipality on pupils' achievement. Variation in the number of schools in a municipality

\footnotetext{
${ }^{17} \mathrm{We}$ control for changes in the composition of the pupil population by including changes in the share of minority pupils in a municipality over time as control variable.

${ }^{18} \chi^{2}(1)=0.053$ and the $p$-value of the test is equal to 0.8187 .
} 
Table 6. Scale versus competition effects

\begin{tabular}{|c|c|c|c|}
\hline & (1) & (2) & (3) \\
\hline $\ln$ (number of schools) & $\begin{array}{c}-0.27^{* *} \\
(0.13)\end{array}$ & $\begin{array}{l}-0.14 \\
(0.13)\end{array}$ & $\begin{array}{l}-0.12 \\
(0.15)\end{array}$ \\
\hline $\ln ($ schoolsize $)$ & & $\begin{array}{l}0.15^{* * *} \\
(0.02)\end{array}$ & $\begin{array}{c}0.17 \\
(0.11)\end{array}$ \\
\hline Instrument $\ln$ (number of schools) & yes & yes & yes \\
\hline Instrument $\ln ($ schoolsize $)$ & $\mathrm{n} / \mathrm{a}$ & no & yes \\
\hline \multicolumn{4}{|l|}{ F statistic 1st stages: } \\
\hline $\begin{array}{l}\ln (\text { number of schools }) \\
\ln (\text { schoolsize })\end{array}$ & 86.8 & 86.4 & $\begin{array}{l}52.2 \\
47.2\end{array}$ \\
\hline Nr municipalities & 345 & 345 & 345 \\
\hline Nr observations & 182509 & 182509 & 182509 \\
\hline
\end{tabular}


causes variation in school choice and competition. The setting of our analysis is primary education in the Netherlands. This setting is very different from the settings of previous papers that looked at the impact of school choice on achievement. While in most countries school choice is limited, primary education in the Netherlands is characterized by a large amount of choice. Parents can freely choose the school of their children and all primary schools are publicly funded through a system in which money follows pupils.

We exploit variation in the number of schools at the level of municipalities induced by a change in the minimum school size rule. Before the change the minimum school size in a municipality was determined by the population size, after the change it was determined by pupil density. Some municipalities were more affected by this change than others. We find a strong effect of the change in the minimum school size on the number of schools in a municipality.

We find a significantly negative effect of the number of schools in a municipality on pupils' achievement. A reduction in the number of schools of 10 percent increases test scores on average by 3 percent of a standard deviation. Hence, more school choice (and competition) is - in the setting of primary education in the Netherlands - detrimental for achievement. Our preferred explanation for this counter-intuitive result comes from the fact that a reduction of the number of schools in a municipality mechanically implies an increase in average school size. The reform reduced the number of small primary schools in the Netherlands. If we include school size in the achievement equation, the negative effect on the number of schools is smaller and no longer statistically significant, and we find nearly identical estimates in an instrumental variable estimation. Information from a survey among principals conducted just prior to the reform is consistent with this: larger schools are associated with more efficient teaching practices while parental involvement does not vary significantly with school size.

Our results call attention to a trade-off that is usually ignored in the school choice and competition literature. If more choice and competition is induced by an increase in the number of suppliers, and if the size of the market is fixed, each supplier will on average serve fewer pupils. Our results show that "scale effects can offset the benefits of competition". The case that we examined in this paper bears some resemblance with the discussion in introductory economics textbooks about the distinction between perfect competition and monopolistic competition. Under monopolistic competition firms operate at a point of their average cost curve tangent to their demand curve. At this point the firm's supply is lower than the amount at which average costs are minimized. The below minimum average costs are usually interpreted as the price customers have to pay for increased product variety. In our setting, pupils paid in the form of lower achievement to attend a smaller school, on average located closer to where they live. 


\section{References}

Abdulkadiroglu, A., Angrist, J., Cohodes, S., Dynarski, S., Fullerton, J., Kane, T., and Pathak, P. (2009). Informing the debate: Comparing Boston's charter, pilot, and traditional public schools. Working Paper.

Andrews, M., Duncombe, W., and Yinger, J. (2002). Revisiting economies of size in American education: are we any closer to a consensus? Economics of Education Review, 21(3):245-262.

Angrist, J., Bettinger, E., Bloom, E., King, E., and Kremer, M. (2002). Vouchers for private schooling in Colombia: Evidence from a randomized natural experiment. American Economic Review, 92(5):1535-1558.

Angrist, J., Bettinger, E., and Kremer, M. (2006). Long-term educational consequences of secondary school vouchers: Evidence from administrative records in Colombia. American Economic Review, 96:847-862.

Berry, C. (2006). School consolidation and inequality. Brookings Papers on Education Policy, pages 49-75.

Berry, C. and West, M. (2008). Growing pains: The school consolidation movement and student outcomes. Journal of Law, Economics, and Organization.

Bettinger, E. (2005). The effect of charter schools on charter students and public schools. Economics of Education Review, 24(2):133-147.

Bifulco, R. and Ladd, H. (2006). The impacts of charter schools on student achievement: Evidence from North Carolina. Education Finance and Policy, 1(1):50-90.

Böhlmark, A. and Lindahl, M. (2008). Does school privatization improve educational achievement? Evidence from Sweden's voucher reform. IZA Discussion Papers.

Brasington, D. (1999). Joint provision of public goods: the consolidation of school districts. Journal of Public Economics, 73(3):373-393.

Brasington, D. (2003). Size and school district consolidation: Do opposites attract? Economica, 70(280):673-690.

Bunschoten, B. (2008). Hoe ver woon ik van ... Bevolkingstrends, 2e kwartaal 2008, pages 19-22. 
Card, D., Dooley, M. D., and Payne, A. A. (2010). School competition and efficiency with publicly funded Catholic schools. American Economic Journal: Applied Economics, 2:150-176.

Cullen, J. B., Jacob, B., and Levitt, S. (2006). The effect of school choice on participants: Evidence from randomized lotteries. Econometrica, 74:1191-1230.

Friedman, M. (1955). The Role of Government in Education. Economics and Public Interest. RA Solo. New Brunswick.

Gibbons, S., Machin, S., and Silva, O. (2008). Choice, competition, and pupil achievement. Journal of the European Economic Association, 6(4):912-947.

Hanushek, E., Kain, J., Rivkin, S., and Branch, G. (2007). Charter school quality and parental decision making with school choice. Journal of Public Economics, 91(56):823-848.

Hoxby, C. (2000). Does competition among public schools benefit students and taxpayers? American Economic Review, 90(5):1209-1238.

Hoxby, C. (2007). Does competition among public schools benefit students and taxpayers? Reply. American Economic Review, 97(5):2038-2055.

Hoxby, C. (2009). School choice and competition. In Hanushek, E. A., Machin, S. J., and Woessmann, L., editors, Handbook of Economics of Education, volume forthcoming. Elsevier North-Holland.

Hoxby, C. and Rockoff, J. (2005). The impact of charter schools on student achievement. Working Paper.

Hsieh, C. and Urquiola, M. (2006). The effects of generalized school choice on achievement and stratification: Evidence from Chile's voucher program. Journal of Public Economics, 90(8-9):1477-1503.

Imberman, S. (2010). Achievement and behavior in charter schools: Drawing a more complete picture. Review of Economics and Statistics, forthcoming.

Krueger, A. and Zhu, P. (2004). Another look at the New York City school voucher experiment. American Behavioral Scientist, 47(5):658.

Kuziemko, I. (2006). Using shocks to school enrollment to estimate the effect of school size on student achievement. Economics of Education Review, 25(1):63-75. 
Ladd, H. (2002). School vouchers: A critical view. Journal of Economic Perspectives, $16: 3-24$.

Lavy, V. (2010). Effects of free choice among public schools. Review of Economic Studies, 77:1164-1191.

Neal, D. (2002). How vouchers could change the market for education. Journal of Economic Perspectives, 16:25-44.

Peterson, P., Howell, W., Wolf, P., and Campbell, D. (2003). School vouchers. Results from randomized experiments. In: C. Hoxby, Editor. The Economics of School Choice.

Rothstein, J. (2007). Does competition among public schools benefit students and taxpayers? Comment. American Economic Review, 97(5):2026-2037.

Rouse, C. (1998). Private school vouchers and student achievement: An evaluation of the Milwaukee parental choice program. Quarterly Journal of Economics, 113(2):553602.

Urquiola, M. (2005). Does school choice lead to sorting? evidence from Tiebout variation. American Economic Review, 95(4):1310-1326.

Williamson, O. (1968). Economies as an antitrust defense: The welfare tradeoffs. The American Economic Review, 58(1):18-36. 


\section{Appendix A: The effect of minimum school size on the share test- takers in a municipality}

Table A: Change in minimum school size rule and the change in share test-takers

$\ln ($ minimum school size rule)

$\begin{array}{ccc}0.006 & 0.008 & 0.008 \\ (0.029) & (0.029) & (0.029) \\ \text { Yes } & \text { Yes } & \text { Yes } \\ \text { Yes } & \text { Yes } & \text { Yes } \\ - & \text { Yes } & \text { Yes } \\ - & - & \text { Yes } \\ & & \\ 345 & 345 & 345 \\ 690 & 690 & 690\end{array}$

Year fixed effects

Municipality fixed effects

Control variables

Allowing for different trends large and small municipalities

$\mathrm{Nr}$ municipalities

690

690

690

Note: Dependent variable: ratio of test participants and the number of 11 year-olds in municipality. Standard errors in parentheses are clustered at the municipality level. Control variables: $\ln (\mathrm{nr}$. pupils), $\ln (\mathrm{nr}$. inhabitants) and municipality share of ethnic minority pupils.Trend in test scores between 1992 and 2003 are allowed to differ between municipalities with number of inhabitants of respectively (0-25000), (2500050000), (50000-100000) and (100000 or more).

\section{Appendix B: Results based on the Herfindahl index}

Table B1: Difference in differences results

\begin{tabular}{lccc} 
& $(1)$ & $(2)$ & $(3)$ \\
\hline Herfindahl index & 0.485 & $0.504^{*}$ & 0.217 \\
& $(0.341)$ & $(0.294)$ & $(0.259)$ \\
Year fixed effects & Yes & Yes & Yes \\
Municipality fixed effects & Yes & Yes & Yes \\
Control variables & - & Yes & Yes \\
Allowing for different trends large & - & - & Yes \\
and small municipalities & & & \\
Nr municipalities & 345 & 345 & 345 \\
Nr observations & 182509 & 182509 & 182509 \\
\hline
\end{tabular}

Note: Dependent variable is standardized test scores. Standard errors in parentheses are clustered at the municipality level. * significant at the $10 \%$ level. Control variables: $\ln (\mathrm{nr}$. pupils), $\ln (\mathrm{nr}$. inhabitants) and municipality share of ethnic minority pupils. Trend in test scores between 1992 and 2003 are allowed to differ between municipalities with number of inhabitants of respectively (0-25000), (25000- 50000), (50000-100000) and (100000 or more). 
(1) (2)

First stage

$\ln$ (minimum school size)

$-0.017 * * *$

$-0.019 * * *$

$(0.003)$

(0.003)

Partial F-statistic

38.7

35.1

Second stage

Herfindahl index

Excluding biggest 20 municipalities

Yes

$\mathrm{Nr}$ municipalities

$\mathrm{Nr}$ observations

Note: Standard errors are clustered at the municipality level. $* *$ significant at the $5 \%$ level, *** significant at the $1 \%$ level. All regression include municipality fixed effects, year fixed effect, control variables: $\ln (\mathrm{nr}$. pupils), $\ln$ (nr. inhabitants), municipality share of ethnic minority pupils and trends are allowed to differ between municipalities with number of inhabitants of respectively (0-25000), (25000- 50000), (50000100000) and (100000 or more). 
Table B3: Scale versus competition effects

\begin{tabular}{lccc}
\hline & $(1)$ & $(2)$ & $(3)$ \\
\hline Herfindahl index & $-3.081^{* *}$ & -1.598 & -1.510 \\
& $(1.547)$ & $(1.554)$ & $(1.934)$ \\
$\ln ($ schoolsize) & & $0.145^{* * *}$ & 0.153 \\
& & $(0.016)$ & $(0.125)$ \\
Instrument ln(\# schools) & yes & yes & yes \\
Instrument ln(schoolsize) & n/a & no & yes \\
& & & \\
F statistic 1st stages: & 38.2 & 36.0 & 19.33 \\
Herfindahl index & & & 47.23 \\
ln(schoolsize) & 345 & 345 & 345 \\
Nr municipalities & 182509 & 182509 & 182509 \\
Nr observations & & & \\
\hline
\end{tabular}

Note: Standard errors in parentheses are clustered at the municipality level. ** significant at the 5\% level, *** significant at the $1 \%$ level. Control variables: $\ln (\mathrm{nr}$. inhabitants) and municipality share of ethnic minority pupils. Trend in test scores between 1992 and 2003 are allowed to differ between municipalities with number of inhabitants of respectively (0-25000), (25000- 50000), (50000- 100000) and (100000 or more). 